This is a post-print version of the paper Sorption of DOM and Hydrophobic Organic Compounds onto Sewage-Based Activated Carbon

The accepted manuscript was published in Water Science and Technology in August 2016.

Björklund, K. and Li, L.Y. (2016) Sorption of DOM and hydrophobic organic compounds onto sewage-based activated carbon. Water Science and Technology 74(4), 852-860. DOI: 10.2166/wst.2016.240 http://wst.iwaponline.com/content/74/4/852 


\title{
Sorption of DOM and Hydrophobic Organic Compounds onto Sewage-Based Activated Carbon
}

Short title: Sorption of DOM and Organic Compounds onto Activated Carbon

\author{
Karin Björklund ${ }^{\text {a, b, * }}$ and Loretta Y. Li ${ }^{\text {a }}$ \\ a Department of Civil Engineering, University of British Columbia, 6250 Applied Science Lane, \\ Vancouver, B.C. Canada V6T 1 Z4 \\ ${ }^{\mathrm{b}}$ Department of Civil and Environmental Engineering, Chalmers University of Technology, Sven Hultins \\ Gata 8, 41296 Göteborg, Sweden \\ ${ }^{*}$ Corresponding author. E-mail address: karin@ @ivil.ubc.ca. Telephone: +1 6048226948 (K. Björklund)
}

\begin{abstract}
Treatment of stormwater via sorption has the potential to remove both colloidal and dissolved pollutants. Previous research shows that activated carbon produced from sewage sludge is very efficient in sorbing hydrophobic organic compounds (HOCs), frequently detected in stormwater. The aim of this research was to determine whether the presence of dissolved organic matter (DOM) has a negative effect on the adsorption of HOCs onto sludge-based activated carbon (SBAC) in batch adsorption tests. Batch adsorption tests were used to investigate the influence of two types of DOM - soil organic matter and humic acid technical standard - on the sorption of HOCs onto SBAC, and whether preloading adsorbent and adsorbates with DOM affects HOC sorption. The results indicate that soil DOM and humic acids do not have a significant negative effect on the adsorption of HOCs under tested experimental conditions, except for a highly hydrophobic compound. In addition, preloading SBAC or HOCs with DOM did not lead to lower adsorption of HOCs. Batch adsorption tests appear to be inefficient for investigating DOM effects on HOC adsorption, as saturating the carbon is difficult because of high SBAC adsorption capacity and low HOC solubility, so that limited competition occurs on the sorbent.
\end{abstract}

Keywords: batch adsorption tests; colloids; competitive adsorption, organic stormwater pollutants; preloading; soil organic matter; 


\section{Frequently used Abbreviations}

DBP - Dibutyl phthalate

DEHP - Di(2-ethylhexyl) phthalate

DOM - Dissolved Organic Matter

HA - Humic Acid

HOC - Hydrophobic Organic Compound

NOM - Natural Organic matter

PAH - Polycyclic Aromatic Hydrocarbon

SBAC - Sludge-Based Activated Carbon 


\section{Post-print version. Accepted paper DOI: 10.2166/wst.2016.240}

\section{Introduction}

Stormwater transports contaminants such as metals, nutrients and anthropogenic organic pollutants generated by construction, transportation and commerce from urban areas into sewer systems and receiving waters. Metals occur in both particulate and dissolved forms in polluted stormwater (Camponelli et al. 2010; Morrison et al. 1990). Recent studies have highlighted that a substantial part of the organic pollutants is also present in the colloidal and dissolved phases (Kalmykova et al. 2013; Kalmykova et al. 2014; Zgheib et al. 2011), despite being hydrophobic by definition and therefore expected to be particle-bound in contaminated waters. Accordingly, stormwater treatment methods cannot rely exclusively on capturing particle-bound pollutants, and additional removal mechanisms for non-particulate pollutants need to be considered.

Treatment of stormwater via sorption has the potential to remove both colloidal and dissolved pollutants. Effective sorbents could be used both as filtration media, e.g. in storm drains, or to enhance pollutant removal as soil amendments, e.g. in rain gardens. Our previous research show that activated carbon produced from sewage sludge is very efficient in sorbing hydrophobic organic compounds (HOCs) frequently detected in stormwater (Björklund and Li, submitted). Sludge-based activated carbon (SBAC) has great potential for stormwater treatment as its production is cost-effective and its adsorption capacity for HOCs is similar to that of commercial carbons. However, our previous study investigated sorption of HOCs onto SBAC where little competition for adsorption sites occurred between HOCs, and from other competing compounds. Stormwater contains a myriad of inorganic and organic compounds, including natural organic matter (NOM) at concentrations between 20 and $30 \mathrm{mg} / \mathrm{L}$ (measured as dissolved organic carbon, DOC) (Helmreich et al. 2010; Kayhanian et al. 2007).

The aim of this research was to determine whether the presence of dissolved organic matter (DOM) has a negative effect on the adsorption of HOCs onto SBAC in batch adsorption tests. According to Wen et al. (2013), the fate of HOCs in water with DOM and SBAC is likely to take four pathways: (1) HOCs attach to SBAC directly; (2) removal through SBAC sorption of HOC-DOM complexes; (3) HOCs remain in solution as truly dissolved compounds; or (4) HOCs remain in solution by attaching to free DOM. The specific objectives of the study were to: (i) examine the influence of two types of DOM - soil organic matter and humic acid technical standard - on the sorption of HOCs onto SBAC; (ii) investigate whether preloading adsorbent and adsorbates with DOM affects HOC sorption onto SBAC. These objectives are based on the following hypotheses: (i) DOM and other colloids enhance the solubility of HOCs in contaminated waters (Badea et al. 2013; Kalmykova et al. 2014; Kim and Kwon 2010); hence HOC sorption 


\section{Post-print version. Accepted paper DOI: 10.2166/wst.2016.240}

onto SBAC is negatively affected by the presence of DOM. In addition, DOM may directly compete with HOCs for adsorption sites on the SBAC surface ( $\mathrm{Li}$ et al. 2003; Pelekani and Snoeyink 1999), leading to lower HOC adsorption; (ii) preloading activated carbon with large organic molecules, such as NOM, leads to pore blocking and results in reduced adsorption of smaller organic pollutants (Li et al. 2003; Quinlivan et al. 2005). In addition, HOCs need time to equilibrate with DOM to form HOC-DOM complexes (Kreeke et al. 2010), which are not adsorbed to the same degree as truly dissolved HOCs (Kalmykova et al. 2014). Hence preloading HOC with DOM affects sorptivity.

This research is part of a study on the use of different sorbents to remove dissolved, hydrophobic pollutants frequently detected in stormwater. The results provide guidance on the selection of efficient sorbents that could be used in field to enhance the capacity of existing stormwater treatment methods to remove pollutants from the water phase.

\section{Materials and Methods}

\section{Physical and Chemical Characteristics of Soil}

Soil was sampled from an operational rain garden (also known as bio-retention) receiving runoff from a roof and a grassed area. Samples were taken from 50-300 $\mathrm{mm}$ below the surface using a clean pail and shovel. The soil, marketed as Cascade Ecomedia, was developed by Cascade Envirotech (Aldergrove, BC, Canada). The reason for using this type of engineered soil was to achieve sufficient DOM concentrations in the eluate, and a large variety of leached DOM. The soil was stored in darkness at $4^{\circ} \mathrm{C}$ prior to use. Determination of $\mathrm{pH}\left(\mathrm{CaCl}_{2}\right.$ method), conductivity, cation exchange capacity ([CEC] ammonium acetate method), particle size distribution (sieve analysis), particle density (pycnometer method), moisture content and loss on ignition (LOI) was performed according to standard methods in Sheldrick (1984). All analyses were performed on triplicate samples (Table 1). 


\section{Post-print version. Accepted paper DOI: 10.2166/wst.2016.240}

Table 1. Physical and chemical characteristics of the soil (average of triplicate samples).

\begin{tabular}{lc}
\hline Parameter & Value \\
\hline $\mathrm{pH}$ & 4.3 \\
Moisture content [\%] & 12.3 \\
Organic content [\%] & 3.75 \\
CEC [meq/100g] & 6.60 \\
Particle density [g/cm $\left.{ }^{3}\right]$ & 2.54 \\
Particle size distribution [\% retained] \\
$1981 \mu \mathrm{m}$ & 5.06 \\
$833 \mu \mathrm{m}$ & 3.33 \\
$500 \mu \mathrm{m}$ & 2.83 \\
$250 \mu \mathrm{m}$ & 44.5 \\
$104 \mu \mathrm{m}$ & 40.9 \\
$74 \mu \mathrm{m}$ & 1.64 \\
bottom pan & 1.96 \\
\hline
\end{tabular}

\section{Sorbent}

The activated carbon used for sorption is produced from sludge from a pilot plant treating domestic sewage from the UBC Campus, Vancouver, Canada. The sludge was first dried, then impregnated with the activation agent $\mathrm{ZnCl}_{2}$ before going through pyrolysis at $\mathrm{T}=500^{\circ} \mathrm{C}$. After pyrolysis, the activated carbon was ground, and washed several times with $\mathrm{HCl}$ and distilled water. Chemicals used in the production of the carbon, as well as the procedure itself and the carbon's characteristics, are described in detail in Gong (2013). In summary, the ash content of the activated carbon was 9\%, BET surface area approximately 700 $\mathrm{m}^{2} / \mathrm{g}$ and $\mathrm{pH}=3.4$.

\section{Batch Leaching Test of Soil}

A batch leaching test was performed to evaluate the release of loosely bound contaminants, which may be mobilized from the soil into the water phase. The leaching test produces eluates characterised by physical and chemical standard methods presented in Table 2 . All quality analyses were performed on eluate passed through a cellulose filter (pore size $0.45 \mu \mathrm{m}$ ). The eluates were further used in the batch adsorption tests. 


\section{Post-print version. Accepted paper DOI: 10.2166/wst.2016.240}

Table 2. Quality of soil eluate and instrumentation used for physical and chemical characterisation (average of triplicate samples).

\begin{tabular}{|c|c|c|}
\hline Parameter & Value & Instrumentation \\
\hline $\mathrm{pH}$ & 5.8 & Oakton $\mathrm{pH} / \mathrm{mV} /{ }^{\circ} \mathrm{C}$ meter, $\mathrm{pH} 11$ series \\
\hline Conductivity $[\mu \mathrm{S} / \mathrm{cm}]$ & 270 & $\begin{array}{l}\text { Radiometer Copenhagen CDM3 } \\
\text { Conductivity meter }\end{array}$ \\
\hline Turbidity [NTU] & 2.3 & Hach 2100P Turbidimeter \\
\hline Dissolved organic carbon (DOC) $[\mathrm{mg} / \mathrm{L}]$ & 6.6 & $\begin{array}{l}\text { Lachat Instrument IL } 500 \text { TOC } \\
\text { analyzer }\end{array}$ \\
\hline Chemical oxygen demand (COD) [mg/L] & 50 & Hach DR 2800 spectrophotometer \\
\hline Biological oxygen demand $\left(\mathrm{BOD}_{5}\right)[\mathrm{mg} / \mathrm{L}]$ & $<6$ & $\begin{array}{l}\text { Hach HQ30d Multi-Parameter Meter } \\
\text { with dissolved oxygen probe }\end{array}$ \\
\hline Nutrients [mg/L] & & Lachat Instrument QuikChem 8000 \\
\hline Phosphate $\left(\mathrm{PO}_{4}{ }^{3-}\right)$ & 0.05 & \\
\hline Ammonium $\left(\mathrm{NH}_{4}^{+}\right)$ & 0.04 & \\
\hline Nitrite $\left(\mathrm{NO}_{2}^{-}\right)$ & $<\mathrm{d} .1 .^{\mathrm{a}}$ & \\
\hline Nitrate $\left(\mathrm{NO}_{3}^{-}\right)$ & 0.99 & \\
\hline Metals $[\mu \mathrm{g} / \mathrm{L}]$ & & $\begin{array}{l}\text { Perkin Elmer Optima } 7300 \text { DV (ICP- } \\
\text { OES) }\end{array}$ \\
\hline $\mathrm{Cd}$ & $<$ d.l. & \\
\hline $\mathrm{Cu}$ & 32 & \\
\hline $\mathrm{Ni}$ & $<$ d.l. & \\
\hline $\mathrm{Pb}$ & 14 & \\
\hline $\mathrm{Zn}$ & $<$ d.1. & \\
\hline
\end{tabular}

${ }^{a}$ Below detection limit

Standard method ISO/TS 21268-2 (2007), adapted to both metals and organic contaminants, was adopted for the leaching tests. In short, the tests were performed at room temperature, using a liquid $\left(0.001 \mathrm{M} \mathrm{CaCl}_{2}\right)$ to solid ( $\leq 2 \mathrm{~mm}$, brass sieve used) ratio of $10 \mathrm{~L} / \mathrm{kg}$ dry matter, and agitated using an end-over-end tumbler for $24 \mathrm{~h}$. As stressed in the standard method, the procedure to separate solids may strongly influence the test results, especially for organic constituents; determining the cut-off for filtration and/or centrifugation is therefore critical. The ISO/TS 21268 advocates filtering eluates through $0.45 \mu \mathrm{m}$ pore size, whereas both Badea et al. (2013) and Bjuggren et al. (1999) suggest that this could lead to loss of analytes on the filter. Instead, centrifugation has been recommended, also in ISO/TS 21268. In this study, we let the eluate samples used in the batch adsorption tests settle for 10-15 $\mathrm{min}$, then centrifuged (2000 rpm for $10 \mathrm{~min}$, to facilitate filtration), and subsequently filtered through baked Whatman 934-AH Glass Microfiber filters (particle retention $1.5 \mu \mathrm{m}$ ). Although all the NOM present in the eluate after filtration is not dissolved by definition, it is hereafter referred to as eluate DOM. 


\section{Post-print version. Accepted paper DOI: 10.2166/wst.2016.240}

\section{Batch Adsorption Tests}

Batch adsorption tests were performed on two types of colloid-containing solutions: eluate from soil leaching tests and synthetic stormwater spiked with humic acids. The eluate was produced in four batches which were then mixed together. Synthetic stormwater was prepared by adding a stock solution of SigmaAldrich humic acids (HAs) standard to ultrapure water. Preparation of the HA stock solution is described by Björklund and $\mathrm{Li}$ (2015). In the adsorption tests, the removals of eluate DOM, humic acids and HOCs were studied (Table 3). All samples were prepared in triplicate. 


\section{Post-print version. Accepted paper DOI: 10.2166/wst.2016.240}

Table 3. Experimental plan for batch adsorption tests using three different solutions (ultrapure water; eluate from soil leaching tests; synthetic stormwater with humic acids [HA]); two added adsorbents (soil organic matter, sewage-based activated carbon [SBAC]); two adsorbates (hydrophobic organic compounds [HOC], dissolved organic matter [DOM]); and contact time (24, 60 h) before solids separation, followed by extraction and analysis.

\begin{tabular}{|c|c|c|c|c|c|c|c|c|c|c|}
\hline & $\begin{array}{l}\text { Centrifugation } \\
\text { vs. Filtration }\end{array}$ & Sorptior & of DOM & Sorption & of HOCs: No p & eloading & & Sorption of $\mathrm{HC}$ & Cs: Preloading & \\
\hline Solution & $\mathrm{H}_{2} \mathrm{O}$ & Eluate & HA & Eluate & HA & $\mathrm{H}_{2} \mathrm{O}^{\mathrm{a}}$ & Eluate & HA & Eluate & HA \\
\hline Adsorbent & $\begin{array}{c}\text { Soil organic } \\
\text { matter }\end{array}$ & SBAC & SBAC & SBAC & SBAC & SBAC & SBAC & SBAC & - & - \\
\hline Adsorbate & HOCs & $\begin{array}{l}\text { Eluate } \\
\text { DOM }\end{array}$ & $\begin{array}{l}\text { Humic } \\
\text { acids }\end{array}$ & HOCs & $\mathrm{HOCs}$ & HOCs & - & - & $\mathrm{HOCs}$ & HOCs \\
\hline $\begin{array}{l}\text { Contact } \\
\text { time (h) }\end{array}$ & 24 & 24 & 24 & 24 & 24 & 24 & 60 & 60 & 24 & 24 \\
\hline $\begin{array}{l}\text { Adsorbent } \\
\text { (preloading } \\
\text { only) }\end{array}$ & & & & & & & - & - & SBAC & SBAC \\
\hline $\begin{array}{l}\text { Adsorbate } \\
\text { (preloading } \\
\text { only) }\end{array}$ & & & & & & & HOCs & HOCs & - & - \\
\hline $\begin{array}{l}\text { Contact } \\
\text { time (h, } \\
\text { preloading } \\
\text { only) }\end{array}$ & & & & & & & 24 & 24 & 24 & 24 \\
\hline $\begin{array}{l}\text { Solids } \\
\text { separation }\end{array}$ & $\begin{array}{l}\text { 1. Centrifugation } \\
\text { 2. Centrifugation } \\
+ \text { filtration (1.5 } \\
\mu \mathrm{m})\end{array}$ & $\begin{array}{c}\text { Filtration } \\
(0.45 \\
\mu \mathrm{m})\end{array}$ & $\begin{array}{c}\text { Filtration } \\
(0.45 \\
\mu \mathrm{m})\end{array}$ & Centrifugation & Centrifugation & Centrifugation & Centrifugation & Centrifugation & Centrifugation & Centrifugation \\
\hline Analyte & $\begin{array}{l}\text { HOCs } \\
\text { DOC }\end{array}$ & DOC & DOC & HOCs & HOCs & HOCs & HOCs & HOCs & HOCs & HOCs \\
\hline
\end{tabular}

${ }^{a}$ Reported in other study (Björklund and Li, submitted) 


\section{Post-print version. Accepted paper DOI: 10.2166/wst.2016.240}

The studied HOCs include three polycyclic aromatic hydrocarbons (PAHs) - fluorene, anthracene and pyrene (octanol-water partition coefficient $\log \mathrm{K}_{\mathrm{ow}}=4.2 ; 4.5 ; 4.9$, respectively); two phthalates - dibutyl phthalate (DBP) and di(2-ethylhexyl) phthalate (DEHP) $\left(\log \mathrm{K}_{\mathrm{ow}}=4.3 ; 7.5\right.$, respectively); and two alkylphenols - octyl- and nonylphenol $\left(\log \mathrm{K}_{\mathrm{ow}}=4.1 ; 4.5\right.$, respectively). Stock and spike solutions of the HOCs were prepared in toluene and acetone, respectively (details in Björklund and Li 2015).

\section{Centrifugation vs. Filtration}

First of all, the effects of particle/colloid separation were studied by centrifugation and filtration of samples with soil organic matter. These tests were a prerequisite for proper handling of samples before extraction and analysis. A soil mass corresponding to $15 \mathrm{mg}$ organic matter (equivalent to SBAC dose used in subsequent tests) was added to ultrapure water $(\mathrm{V}=150 \mathrm{~mL})$ and spiked ultrapure water $\left(\mathrm{V}=150 \mathrm{~mL}, \mathrm{C}_{\mathrm{i}}=100\right.$ $\mu \mathrm{g} / \mathrm{L}$ of each HOC), and the solution was mixed for $24 \mathrm{~h}$. The samples were next settled for 10-15 min, then either centrifuged (2000 rpm, $10 \mathrm{~min}$ ) or centrifuged and filtered through Whatman 934-AH (Table 3). The samples were analyzed for the remaining DOC and HOC concentrations. The DOC concentrations were determined using a Lachat Instrument IL 500 TOC analyzer.

\section{Sorption of DOM onto SBAC}

Adsorption of DOM onto SBAC was tested using eluate (dose SBAC $=15 \mathrm{mg}, \mathrm{C}_{\mathrm{i}}=9 \mathrm{mgDOC} / \mathrm{L}, \mathrm{V}=50 \mathrm{~mL}$ ) and synthetic stormwater (dose $\mathrm{SBAC}_{\mathrm{C}}=100 \mathrm{mg}, \mathrm{C}_{\mathrm{i}}=120 \mathrm{mgDOC} / \mathrm{L}, \mathrm{V}=50 \mathrm{~mL}$ ). After $24 \mathrm{~h}$ of contact, the samples were filtered through a $0.45 \mu \mathrm{m}$ cellulose nitrate filter (Millipore), before analysis of DOC concentrations (Table 3). Initial DOC concentrations in eluate and synthetic stormwater were tested on filtered $(0.45 \mu \mathrm{m})$ samples.

\section{Sorption of HOCs onto SBAC}

The batch adsorption tests of HOCs were performed in a manner similar to a previous study (no addition of DOM) in order to obtain comparable results (Björklund and Li, submitted). In the HOCs tests, $150 \mathrm{~mL}$ eluate/synthetic stormwater was spiked with a mixture of the seven HOCs $\left(\mathrm{C}_{\mathrm{i}}=100 \mu \mathrm{g} / \mathrm{L}\right.$ for each compound), and $15.0 \mathrm{mg}$ SBAC was contacted with the solution for $24 \mathrm{~h}$ using an end-over-end tumbler at room temperature $\left(20 \pm 2^{\circ} \mathrm{C}\right)$. Samples were then centrifuged $(2000 \mathrm{rpm}, 10 \mathrm{~min})$ to separate the SBAC from the water phase, which was extracted and analyzed for remaining HOC concentrations (Table 3). Adsorption was also tested at five different initial HOC concentrations $\left(\mathrm{C}_{\mathrm{i}}=10-300 \mu \mathrm{g} / \mathrm{L}, \mathrm{V}=150 \mathrm{~mL}\right)$ contacted with SBAC (15.0 mg) in ultrapure water (Björklund and $\mathrm{Li}$, submitted) and synthetic stormwater (current study). For all batches, matrix blanks $\left(0.001 \mathrm{M} \mathrm{CaCl}_{2}\right.$, eluate or synthetic stormwater) and a matrix 


\section{Post-print version. Accepted paper DOI: 10.2166/wst.2016.240}

spike were prepared following the same procedure to determine contamination and loss of analytes, respectively.

In the preloading batch tests, $\mathrm{SBAC}(15.0 \mathrm{mg})$ was contacted with eluate $\left(\mathrm{V}=150 \mathrm{~mL}, \mathrm{C}_{\mathrm{i}}=9 \mathrm{mg} \mathrm{DOC} / \mathrm{L}\right)$ and synthetic stormwater $\left(\mathrm{V}=150 \mathrm{~mL}, \mathrm{C}_{\mathrm{i}}=14 \mathrm{mg} \mathrm{DOC} / \mathrm{L}\right)$ for $60 \mathrm{~h}$ before HOCs $\left(\mathrm{C}_{\mathrm{i}}=100 \mu \mathrm{g} / \mathrm{L}\right.$ for each compound) were added and contacted with the solution and SBAC for an additional $24 \mathrm{~h}$ (Table 3). In addition, synthetic stormwater and eluate $(\mathrm{V}=150 \mathrm{~mL})$ were contacted with HOCs $\left(\mathrm{C}_{\mathrm{i}}=100 \mu \mathrm{g} / \mathrm{L}\right.$ of each compound) for $24 \mathrm{~h}$ before SBAC (15.0 mg) was added and contacted with the solution for an additional $24 \mathrm{~h}$. The subsequent test procedure was the same as described above.

\section{Extraction and Analysis of Organic Compounds}

The organic compounds were liquid-liquid extracted from the water phase using dichloromethane (DCM). Identification and quantification were performed using a 6890 HP/Agilent GC system gas chromatograph with a 6890 series injector and a quadrupole 5973 network mass selective detector (Agilent Technologies, Wilmington, USA). Details on the extraction procedure, instrumental analysis, as well as all chemicals used in these procedures, including standard solutions, are found in Björklund and Li (2015).

\section{Data Analysis}

Adsorption capacity, $\mathrm{q}_{\mathrm{e}}(\mu \mathrm{g} / \mathrm{g})$, of $\mathrm{SBAC}$ was calculated using:

$\mathrm{q}_{\mathrm{e}}=\frac{\left(\mathrm{C}_{\mathrm{i}}-\mathrm{C}_{\mathrm{e}}\right) \cdot \mathrm{V}}{\mathrm{m}}$

where $C_{i}$ is the initial concentration of HOCs $[\mu \mathrm{g} / \mathrm{L}] ; \mathrm{C}_{\mathrm{e}}$ is the residual HOC concentration in solution at equilibrium $[\mu \mathrm{g} / \mathrm{L}]$; $\mathrm{V}$ is the solution volume $[\mathrm{L}]$; and $\mathrm{m}$ is the mass of sorbent $[\mathrm{g}]$.

All statistical analyses were performed using IBM SPSS Statistics Version 20.

\section{Results and Discussion}

\section{Leaching Test}

The eluate quality revealed low contamination of metals (Table 2), and the HOCs could not be detected in the soil eluate. The only exception was DEHP $(\overline{\mathrm{x}}=1.13 \mu \mathrm{g} / \mathrm{L})$, although its presence in the eluates is likely 


\section{Post-print version. Accepted paper DOI: 10.2166/wst.2016.240}

due to contamination during sample handling and analysis, as similar concentrations were found in blank samples $(\overline{\mathrm{x}}=0.81 \mu \mathrm{g} / \mathrm{L})$. The soil was sampled from a rather new rain garden (1.5 year operation time). Low contamination from HOCs was therefore expected.

\section{Filtration Effects on Detected HOC and DOM Concentrations}

Compared to using centrifugation alone, filtration reduced the detected concentration of the most hydrophobic compound, DEHP, by 65\%; nonylphenol, DBP, anthracene and pyrene by 13-17\%; and negligibly for fluorene and octylphenol. The decreases in detected concentrations following filtration are highly correlated to the compounds' $\log \mathrm{K}_{\mathrm{ow}}$ (Spearman's $\rho=0.883, \mathrm{p}=.008$, 2-tailed). It should be noted that in a test batch with spiked ultrapure water $\left(\mathrm{C}_{\mathrm{i}}=100 \mu \mathrm{g} / \mathrm{L}\right.$ of each $\mathrm{HOC}$, no sorbent addition $)$, the recoveries of HOCs were not affected by filtration through Whatman 934-AH. The exception was DEHP, for which the recovery was substantially reduced from 82 to $25 \%$ after filtration.

Soil DOM decreased from approximately $56 \mathrm{mgDOC} / \mathrm{L}$ to $17 \mathrm{mgDOC} / \mathrm{L}$ after filtration, i.e. a $60 \%$ decrease, which is not in proportion with the decrease in HOC concentrations after filtration (0-17\%, DEHP excepted). The small decrease in HOCs concentrations after filtration suggests that the compounds especially the less hydrophobic ones - are mainly present either in dissolved form or attached to DOM smaller than $1.5 \mu \mathrm{m}$. The exception to this conclusion could be DEHP, although it is not certain whether the decrease in detected concentrations after filtration is exclusively due to DEHP molecules adhering to the filter material, or also partly due to DEHP-DOM complexes becoming trapped by the filter. 


\section{Solution Type Effects on Adsorption Capacity}

(a)

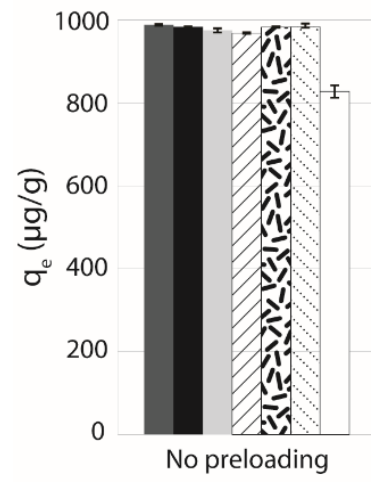

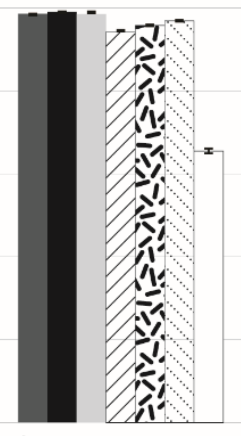

Eluate DOM + SBAC

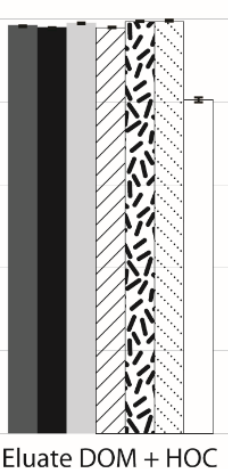

(b)

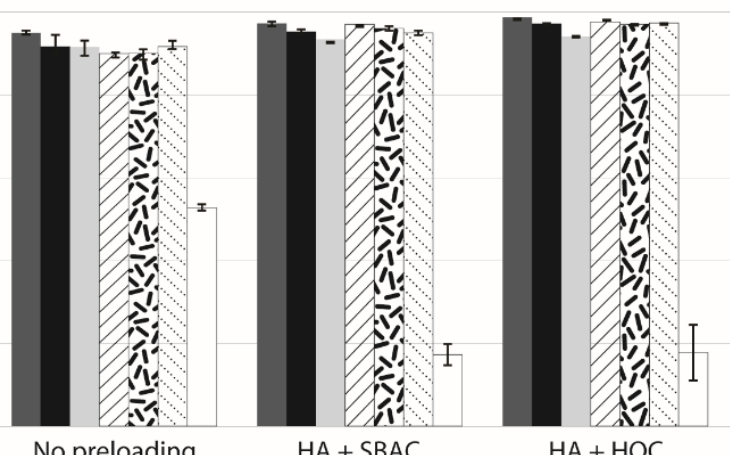

No preloading

$\mathrm{HA}+\mathrm{SBAC}$

$\mathrm{HA}+\mathrm{HOC}$

Preloading condition

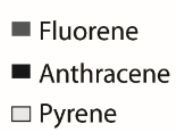

$\square$ Octylphenol

$\square$ Dibutyl phthalate

$\square$ Di(2-ethylhexyl) phthalate

Figure 1. Mean adsorption capacity $\left(q_{e}\right)$ of HOCs onto SBAC using (a) soil eluate and $(b)$ synthetic stormwater as test solutions at different eluate DOM and humic acids (HA) preloading conditions. Error bars indicate standard error of $q_{e}$.

To investigate the effect of DOM on HOC adsorption, results from batch tests with eluate and synthetic stormwater were compared to results from a previous study (Björklund and $\mathrm{Li}$, submitted) where ultrapure water was used as sample solution (SBAC dose and HOC concentrations same as in the current study). Approximately $1-5 \%$ of the initial HOC concentration remained in the spiked soil eluate after $24 \mathrm{~h}$ of contact with SBAC. This corresponds to an adsorption capacity of 970-990 $\mu \mathrm{g} / \mathrm{g}$ per compound, adding up to $6.7 \mathrm{mg} / \mathrm{g}$ for all HOCs under the test experimental conditions (Figure 1a, no preloading). Similar adsorption capacities were found in samples with synthetic stormwater (Figure 1b, no preloading) and ultrapure water. A one-way ANOVA reveals that there is no significant difference in $q_{e}$ at the $\mathrm{p}<0.05$ level for the three solutions $[F(2,18)=1.572, p=0.235]$.

Testing different initial HOC concentrations verified HA's low effect on adsorption. In general, nonsignificant differences in $q_{e}$ were observed between water and HA samples (Mann-Whitney U=28.00, $\mathrm{p}=0.674$, 2-tailed) for all five concentrations. The exception is DEHP, for which $q_{e}$ in water samples were approximately 30-60\% higher than in HA-solution at different $C_{i}$. These results indicate that DOM in the form of pure HAs does not have a significant negative effect on the adsorption of HOCs under the current experimental conditions, except for the highly hydrophobic DEHP. 


\section{Post-print version. Accepted paper DOI: 10.2166/wst.2016.240}

\section{Preloading Effects on Adsorption Capacity}

Preloading SBAC with eluate DOM did not lead to an apparent difference in adsorption capacities of HOCs compared to no preloading (Figure 1a, eluate DOM+SBAC). However, DEHP exhibited a decrease in $q_{e}$ from 820 to $650 \mu \mathrm{g} / \mathrm{g}$ when SBAC was preloaded with DOM. Contrary to what was suggested by Kreeke et al. (2010), 24 h of pre-contact between eluate DOM and HOCs before adding SBAC had no effect on HOC adsorption, including DEHP adsorption (Figure 1a, eluate DOM+HOC). There was no significant difference in $q_{e}$ at the $\mathrm{p}<0.05$ level for the three conditions (i.e. no preloading, preloading eluate $\mathrm{DOM}+\mathrm{SBAC}$, preloading eluate $\mathrm{DOM}+\mathrm{HOC})[\mathrm{F}(2,53)=0.855, \mathrm{p}=0.419]$.

Similarly, preloading SBAC with HA in synthetic stormwater did not lead to lower adsorption of HOCs, DEHP again being an exception, compared to samples where HOCs and HA were added simultaneously (Figure 1b, HA+SBAC). Preloading did not significantly affect $q_{e}$ at the $\mathrm{p}<0.05$ level for the three conditions (i.e. no preloading, preloading $\mathrm{HA}+\mathrm{SBAC}$, preloading $\mathrm{HA}+\mathrm{HOC})[\mathrm{F}(2,39)=0.017$, p=0.983]. It is apparent, however, that the capacity of SBAC to adsorb DEHP is negatively affected by the presence of humic acids, which was also noticed when comparing the ultrapure water and synthetic stormwater at different HOC concentrations. For no pre-contact between HA and HOC or SBAC, average $q_{e, D E H P}$ was 520 $\mu \mathrm{g} / \mathrm{g}$ (Figure 1b, no pre-loading) compared to $820 \mu \mathrm{g} / \mathrm{g}$ in eluate solution (Figure 1a, no pre-loading). In addition, pre-contact between HA and SBAC and HA and HOC reduced $q_{e, D E H P}$ further to 180 and 170 $\mu \mathrm{g} / \mathrm{g}$, respectively (Figure 1b, pre-loading HA+SBAC and HA+HOC).

\section{Effects of DOM and Preloading}

Given the high removal rate (approximately 95\%) of HOCs from both spiked eluate and synthetic stormwater with HA, HOCs remaining in solution as truly dissolved compounds (suggested pathway 3, Wen et al. 2013) or HOCs remaining in solution by attaching to free DOM (pathway 4), are not considered major pathways in this case, and HOCs are either directly adsorbed to SBAC, or through sorption of HOCDOM complexes. The lack of effect of pre-loading HOCs with DOM (Figure 1a and b) is in agreement with suggested dominant pathways. This non-effect is either a result of limited formation of HOC-DOM complexes, i.e. HOCs attach to SBAC directly (pathway 1), or that pre-loading time is not relevant as HOCDOM complexes form immediately, and that these complexes are adsorbed onto SBAC, i.e. HOC removal through SBAC sorption of HOC-DOM complexes (pathway 2). 


\section{Post-print version. Accepted paper DOI: 10.2166/wst.2016.240}

Eluate contacted with $\mathrm{SBAC}$ (dose ${ }_{\mathrm{SBAC}}=15.0 \mathrm{mg}, \mathrm{C}_{\mathrm{i}, \mathrm{DOM}}=9 \mathrm{mgDOC} / \mathrm{L}$, no HOCs) led to a $44 \%$ decrease in the initial DOC concentration. In addition, a saturation test revealed that approximately $19 \mathrm{mg}$ HA was adsorbed per $\mathrm{g}$ SBAC (dose $\mathrm{SBAC}_{\mathrm{B}}=100 \mathrm{mg}, \mathrm{C}_{\mathrm{i}, \mathrm{HA}}=120 \mathrm{mgDOC} / \mathrm{L}$ ). These results show that $\mathrm{DOM}$ in eluate and synthetic stormwater is indeed sorbed onto SBAC, suggesting that HOCs may be removed from the water phase through adsorption of HOC-DOM complexes, if these are formed. There are, however, two factors indicating that removal of HOC-DOM complexes may not be a major pathway.

Firstly, results presented by Comans et al. (2001) suggest that HOCs do not bind to DOM colloids $<0.45$ $\mu \mathrm{m}$ in synthetic stormwater or eluate. Comans et al. used size exclusion chromatography to show that the high-molecular fraction of soil DOC, assumed to be the most hydrophobic fraction (Shin et al. 1999), is responsible for the solubility enhancement of PAHs in water and that the $<0.45 \mu \mathrm{m}$ fraction does not bind to PAHs to a considerable degree. In this study, no significant difference in $q_{e}$ was found between eluate $(<1.5 \mu \mathrm{m})$ and synthetic stormwater $(<0.45 \mu \mathrm{m})$ tests, and the centrifugation vs. filtration tests indicated that more than $80 \%$ of the HOCs (DEHP excepted) were found in DOM $<1.5 \mu \mathrm{m}$, or in the dissolved phase. Taken together, this suggests that HOCs bind only to DOM $0.45-1.5 \mu \mathrm{m}$ in size, or, more likely, that HOCDOM complexes are not formed to a large degree. Hence removal by HOCs attaching directly to SBAC is dominant (pathway 1).

The second factor pointing against HOC-DOM complexes is hydrophobic partitioning. Fulvic and humic acids make up the bulk of organic matter in natural waters and are the major organic constituents in soil (Bedding et al. 1982). Hence, DOM in soil eluates can be assumed to contain mostly these natural acids. Binding of HOCs to humics is promoted by a large aromatic content and a rather low content of functional groups in the humic structures (De Paolis and Kukkonen 1997; Suffet et al. 1994). In general, non-polar molecules, such as the studied HOCs, interact with the non-polar or hydrophobic part of humics. Given the abundance of hydrophobic sites on activated carbon (Bansal and Goyal 2005), it may be assumed that HOCs are more attracted to SBAC than to humics, which also contain many hydrophilic parts, in both the eluate and the synthetic stormwater. Hence removal by HOCs attaching directly to SBAC is dominant (pathway $1)$.

The batch adsorption tests suggest little or no formation of HOC-DOM complexes, although other studies (e.g. Kalmykova et al. 2013; Kalmykova et al. 2014) show that HOCs do indeed attach to DOM in natural waters, for example stormwater and landfill leachate. Conditions in natural waters are different from batch test samples and HOC-DOM complexes may be formed in natural waters due to longer contact time 


\section{Post-print version. Accepted paper DOI: 10.2166/wst.2016.240}

between HOCs and DOM, and due to the presence of many different types of DOM, which may be more or less attractive for HOCs.

Although HOC-DOM complexes may not form to a large extent in the batch tests, DOM may still exert negative effects on HOC adsorption through competition. Competitive adsorption of organic compounds and DOM onto activated carbon occurs through two proposed mechanisms: (a) direct competition for available adsorption sites, which occurs when the DOM molecular size is similar to that of the organic compound; and (b) blockage of larger pores, caused by larger molecules obstructing the entrance of smaller pores (Kilduff et al. 1996; Li et al. 2003). Since micropores ( $<20 \AA)$, where HOCs tend to sorb, are inaccessible to large DOM molecules, direct competition is not likely in this case (Li et al. 2003; Pelekani and Snoeyink 1999; Quinlivan et al. 2005). The diffusion of small compounds (compounds studied are 166-278 Da, DEHP excepted) is faster than that of larger DOM molecules, and the compounds can enter small pores before the large DOM molecules accumulate on the carbon surface and block the pores. Hence, pore blocking is often limited in batch systems without pre-loading (Kilduff et al. 1996; Quinlivan et al. 2005). However, pre-loading exhibited very limited effects on HOC adsorption in the current study. This is likely a result of the low concentrations of HOCs $(100 \mu \mathrm{g} / \mathrm{L}$ of each compound) and DOM (10-20 $\mathrm{mgDOC} / \mathrm{L}$ ), which were not sufficient to saturate SBAC adsorption sites, so that there was low competition between DOM and HOCs, and between different HOCs. Our previous research (Björklund and Li, submitted) showed that when saturation of SBAC occurs (achieved through repeated adsorption, used in lieu of high concentrations due to the HOCs' low solubility), the less hydrophobic compounds fluorene, octylphenol and DBP $\left(\log \mathrm{K}_{\mathrm{ow}} 4.2-4.3\right)$ reached breakthrough before the more hydrophobic pyrene and

DEHP (log $\mathrm{K}_{\mathrm{ow}} 4.9$ and 7.7). Adsorbed loads of each HOC were strongly correlated to compound $\log \mathrm{K}_{\mathrm{ow}}$ ( $\rho=0.883$ ). The $\mathrm{K}_{\mathrm{ow}}$ for different types of humic acids are usually below 0 (Schramm et al. 1998), i.e. several order of magnitudes lower than the tested organic compounds. Hence, when competitive adsorption between HOCs and humic acids occurs, the high $\mathrm{K}_{\mathrm{ow}}$ :s of HOCs are likely to work in favour of HOC adsorption onto the hydrophobic carbon surface.

In continuous flow adsorption systems, for example in column studies, the adsorbent is initially only partially loaded with DOM and organic compounds, but more organic compounds and DOM continuously enter the system. Li et al. (2003) studied sorption of the pesticide atrazine (216 Da) in both batch and continuous flow systems and found that atrazine removal in the continuous system was $30 \%$ lower because of the pore blockage effect of NOM. It is therefore advisable to use continuous flow systems to test HOC sorption before SBAC, and other adsorbents, are applied in filters for stormwater treatment. In addition, 


\section{Post-print version. Accepted paper DOI: 10.2166/wst.2016.240}

continuous flow systems are useful for testing the adsorption capacity at contact times which are similar to those in operating adsorption filters.

The exception in most batch adsorption tests was DEHP, the only HOC substantially affected by the presence of DOM. In fact, DEHP adsorption was most negatively affected by technical grade HAs $(<0.45$ $\mu \mathrm{m})$, both with and without pre-loading, and not particularly affected by the presence of soil DOM. These results are contrary to results from Comans et al. (2001), which suggest that HOCs are not attached to colloids $<0.45 \mu \mathrm{m}$. The reason for these different findings is unknown at this moment. Given that DEHP exhibits such extreme hydrophobicity $\left(\log \mathrm{K}_{\mathrm{ow}}=7.5\right)$, its molecules will likely attach to anything hydrophobic, both DOM and SBAC, rather than being dissolved in the water phase. Competitive adsorption appears to occur as DEHP sorption is negatively affected by pre-loading SBAC with eluate DOM and HA as well as with HOCs (Figure 1a and b). The remaining high concentrations of DEHP found in samples with DOM may be due to greater competition between the large phthalate molecule (391 Da) and DOM, than other studied HOCs. In addition, DEHP, and to a lesser degree pyrene, may occur as emulsions at the concentrations tested (Julinová and Slavík 2012), due the low water solubility (DEHP $2.5 \cdot 10^{-3} \mathrm{mg} / \mathrm{L}$; pyrene $7.7 \cdot 10^{-2} \mathrm{mg} / \mathrm{L}$, all other HOCs $>1 \mathrm{mg} / \mathrm{L}$ ), and the DEHP droplets may be subject to direct competition with similar sized DOM. However, this idea cannot be verified as emulsion formation and potential droplet size were not tested in this study.

\section{Conclusions}

Batch tests performed using soil eluate and synthetic stormwater indicate that the presence of soil DOM $(<1.5 \mu \mathrm{m})$ and technical grade humic acids $(<0.45 \mu \mathrm{m})$ does not affect the sorption of hydrophobic organic compounds ( $\left.\log \mathrm{K}_{\mathrm{ow}} 4-5\right)$ onto sludge-based activated carbon under the experimental conditions tested $\left(\mathrm{C}_{\mathrm{i}, \mathrm{HOC}}=100 \mu \mathrm{g} / \mathrm{L}, \mathrm{C}_{\mathrm{i}, \mathrm{DOM}}=9-20 \mathrm{mgDOC} / \mathrm{L}\right.$, dose $\left.{ }_{\mathrm{SBAC}}=15.0 \mathrm{mg}, \mathrm{V}=150 \mathrm{~mL}\right)$. This lack of effect suggests that DOM in the solutions does not compete with HOCs for adsorption sites on the activated carbon surface, and that the formation of dissolved HOC-DOM complexes is limited. The assumed low formation of HOCDOM complexes may be due to short equilibration time $(24 \mathrm{~h})$ between HOCs and DOM compared to contact times in natural waters, and limited attraction between HOCs and small, predominantly hydrophilic colloids. We conclude that batch adsorption tests are not efficient for investigating DOM effects on adsorption of hydrophobic organic compounds onto activated carbon, as the compounds' low water solubility, and the high adsorption capacity of activated carbon do not lead to saturation of the carbon, so that little competition for adsorption sites occurs. Before SBAC and other sorbents are applied in filters for stormwater treatment, sorption in continuous flow systems using natural stormwater with NOM and other 


\section{Post-print version. Accepted paper DOI: 10.2166/wst.2016.240}

present pollutants, including metals and organic compounds, should be tested to fully explore the effect of DOM and contact time on removal of organic pollutants.

\section{Acknowledgements}

The Swedish Research Council Formas (grant 245-2012-1607), Ollie och Elof Ericssons stiftelse för vetenskaplig forskning, and the Natural Sciences and Engineering Research Council of Canada (RGPIN 185040-12) are gratefully acknowledged for funding this research. We thank Andrew Kolper at Kerr Wood Leidal Associates Ltd. for performing the soil sampling.

\section{References}

Badea S.L., Lundstedt S., Liljelind P. and Tysklind M. 2013 The influence of soil composition on the leachability of selected hydrophobic organic compounds (HOCs) from soils using a batch leaching test. Journal of Hazardous Materials, 254-255, 26-35. doi: 10.1016/j.jhazmat.2013.03.019.

Bansal R.C. and Goyal M. 2005 Activated Carbon Adsorption. CRC Press, Boca Raton. doi: $10.1201 / 9781420028812$

Bedding N.D., McIntyre A.E., Perry R. and Lester J.N. 1982 Organic contaminants in the aquatic environment I. Sources and occurrence. Science of the Total Environment, 25(2), 143-167. doi: 10.1016/0048-9697(82)90083-3.

Björklund K. and Li L. Adsorption of Organic Stormwater Pollutants onto Activated Carbon from Sewage Sludge. Submitted.

Björklund K. and Li L. 2015 Evaluation of low-cost materials for sorption of hydrophobic organic pollutants in stormwater. Journal of Environmental Management, 159, 106-114. doi:10.1016/j.jenvman.2015.05.005.

Bjuggren C., Fortkamp U. and Remberger M. 1999 Laktest för organiska ämnen i jord - utveckling av testmetod (Leaching test for organic compounds in soil - development of test method), Report number: B1339, IVL Svenska Miljöinstitutet, Stockholm, Sweden.

Camponelli K.M., Lev S.M., Snodgrass J.W., Landa E.R. and Casey R.E. 2010 Chemical fractionation of $\mathrm{Cu}$ and $\mathrm{Zn}$ in stormwater, roadway dust and stormwater pond sediments. Environmental Pollution, 158(6), 2143-2149. doi:10.1016/j.envpol.2010.02.024.

Comans R.N.J., Roskam G., Oosterhoff A., Shor L., Wahlstrom M., Laine-Ylijoki J., Pihlajaniemi M., Ojala M., Broholm K., Villholth K., Hjelmar O., Heimovaara T., Keijzer J. and Keijzer H. 2001 Development of standard leaching tests for organic pollutants in soils, sediments and granular waste materials: final report, Report number: ECN-C--01-121, Energy research Centre of the Netherlands (ECN), Petten, the Netherlands.

De Paolis F. and Kukkonen J. 1997 Binding of organic pollutants to humic and fulvic acids: Influence of $\mathrm{pH}$ and the structure of humic material. Chemosphere, 34(8), 1693-1704. doi: 10.1016/S00456535(97)00026-X.

Gong X. 2013 Modification and utilization of sewage sludge-based activated carbon as metal adsorbents. Master thesis, University of British Columbia, Vancouver, BC, Canada. doi: 10.14288/1.0074198 .

Helmreich B., Hilliges R., Schriewer A. and Horn H. 2010 Runoff pollutants of a highly trafficked urban road - Correlation analysis and seasonal influences. Chemosphere, 80(9), 991-997. doi: 10.1016/j.chemosphere.2010.05.037. 


\section{Post-print version. Accepted paper DOI: 10.2166/wst.2016.240}

International Organization for Standardization (ISO). 2007 ISO/TS 21268-2: Soil quality — Leaching procedures for subsequent chemical and ecotoxicological testing of soil and soil materials. Part 2: Batch test using a liquid to solid ratio of $10 \mathrm{l} / \mathrm{kg}$ dry matter.

Julinová M. and Slavík R. 2012 Removal of phthalates from aqueous solution by different adsorbents: A short review. Journal of Environmental Management, 94(1), 13-24. doi: 10.1016/j.jenvman.2011.09.006.

Kalmykova Y., Björklund K., Strömvall A.M. and Blom L. 2013 Partitioning of polycyclic aromatic hydrocarbons, alkylphenols, bisphenol A and phthalates in landfill leachates and stormwater. Water Research, 47(3), 1317-1328. doi: 10.1016/j.watres.2012.11.054.

Kalmykova Y., Moona N., Strömvall A.M. and Björklund K. 2014 Sorption and Degradation of Petroleum Hydrocarbons, Polycyclic Aromatic Hydrocarbons, Alkylphenols, Bisphenol A and Phthalates in Landfill Leachate Using Sand, Activated Carbon and Peat Filters. Water Research, 56, 246-257. doi: 10.1016/j.watres.2014.03.011.

Kayhanian M., Suverkropp C., Ruby A. and Tsay K. 2007 Characterization and prediction of highway runoff constituent event mean concentration. Journal of Environmental Management, 85(2), 279295. doi: 10.1016/j.jenvman.2006.09.024.

Kilduff J.E., Karanfil T. and Weber W.J. 1996 Competitive Interactions among Components of Humic Acids in Granular Activated Carbon Adsorption Systems: Effects of Solution Chemistry. Environmental Science \& Technology, 30(4), 1344-1351. doi: 10.1021/es950546z.

Kim S.J. and Kwon J.H. 2010 Determination of Partition Coefficients for Selected PAHs between Water and Dissolved Organic Matter. CLEAN - Soil, Air, Water, 38(9), 797-802. doi: 10.1002/clen.201000113.

van der Kreeke J., de la Calle B., Held A., Bercaru O., Ricci M., Shegunova P. and Taylor P. 2010 IMEP23: The eight EU-WFD priority PAHs in water in the presence of humic acid. TrAC Trends in Analytical Chemistry, 29(8), 928-937. doi: 10.1016/j.trac.2010.04.009.

Li Q., Snoeyink V.L., Mariñas B.J. and Campos C. 2003 Pore blockage effect of NOM on atrazine adsorption kinetics of PAC: the roles of PAC pore size distribution and NOM molecular weight. Water Research, 37(20), 4863-4872. doi: 10.1016/j.watres.2003.08.018.

Morrison G.M.P., Revitt D.M. and Ellis J.B. 1990 Metal speciation in separate stormwater systems. Water Science and Technology, 22(10-11), 53-60. doi: 10.1080/09593338709384496.

Pelekani C. and Snoeyink V.L. 1999 Competitive adsorption in natural water: role of activated carbon pore size. Water Research, 33(5), 1209-1219. doi: 10.1016/S0043-1354(98)00329-7.

Quinlivan P.A., Li L. and Knappe D.R.U. 2005 Effects of activated carbon characteristics on the simultaneous adsorption of aqueous organic micropollutants and natural organic matter. Water Research, 39(8), 1663-1673. doi: 10.1016/j.watres.2005.01.029.

Sheldrick B.H. 1984. Analytical Methods Manual. Land Resource Research Institute, Research Branch, Agriculture Canada, Ottawa, Canada.

Shin H.S., Monsallier J.M. and Choppin G.R. 1999 Spectroscopic and chemical characterizations of molecular size fractionated humic acid. Talanta, 50(3), 641-647. doi: 10.1016/S00399140(99)00161-7.

Schramm K.W., Behechti A., Beck B. and Kettrup A. 1998 Influence of an Aquatic Humic Acid on the Bioconcentration of Selected Compounds in Daphnia magna. Ecotoxicology and Environmental Safety, 41(1), 73-76. doi: 10.1006/eesa.1998.1669.

Suffet I.H., Jafvert C.T., Kukkonen J., Servos M.R., Spacie A., Williams L.L. and Noblet J.A. 1994 Synopsis of Discussion Session: Influences of Particulate and Dissolved Material on the Bioavailability of Organic Compounds. In: Bioavailability: Physical, Chemical, and Biological Interactions, Hamelink J., Landrum P.F., Bergman H. and Benson W.H. (eds.), Lewis Publishers, Boca Raton, pp. 93-108. 
Wen Z.D., Gao D.W., Li Z. and Ren N.Q. 2013 Effects of humic acid on phthalate adsorption to vermiculite. Chemical Engineering Journal, 223, 298-303. doi: 10.1016/j.cej.2013.03.012.

Zgheib S., Moilleron R., Saad M. and Chebbo G. 2011 Partition of pollution between dissolved and particulate phases: what about emerging substances in urban stormwater catchments? Water Research, 45(2), 913-925. doi: 10.1016/j.watres.2010.09.032. 